\title{
La relevancia contemporánea de Marx ${ }^{1}$
}

\author{
The contemporary relevance of Marx
}

Claudio Katz

CONICET (Argentina)

\section{RESUMEN}

La obra de Marx ha recuperado interés en los últimos tiempos. Su clarificación del funcionamiento del capitalismo contrasta con las simplificaciones neoclásicas y las ingenuidades heterodoxas. Este autor indicó la lógica de la plusvalía que subyace en la agresión neoliberal y el tipo de superexplotación que prevalece en el trabajo precario. Esclareció el origen de la desigualdad y el sentido actual del beneficio.

El capital permite refutar la identificación de la revolución digital con el desempleo. Cuestiona las explicaciones de la crisis por desaciertos gubernamentales o carencias de regulaciones. Remarca tensiones intrínsecas en la esfera del consumo y la rentabilidad.

Marx subrayó los determinantes productivos de las convulsiones financieras. Sugirió las conexiones de la mundialización con los patrones nacionales de acumulación. Anticipó las polarizaciones que generan subdesarrollo en la periferia y los vínculos del antiimperialismo con estrategias socialistas.

\footnotetext{
${ }^{1}$ Este artículo sintetiza ideas expuestas en Katz Claudio. La economía marxista, hoy. Seis debates teóricos, Maia, Madrid, 2009. Neoliberalismo, Neodesarrollismo, Socialismo, Batalla de Ideas, 2016, Buenos Aires. Marx y la periferia, www.rebelion, 28/3/2016. TheManifesto and Globalization, Latin American Perspectives, Issue 117, Vol. 28 No. 5, September 2001. La bibliografía completa puede consultarse en esos textos.
} 
También conceptualizó la combinación de ilusiones y temor que propaga la ideología burguesa. Su proyecto igualitario resurge junto a nuevas síntesis de la acción política con la elaboración teórica.

PALABRAS CLAVE: Marx, El capital, Capitalismo, neoliberalismo, marxismo

\section{ABSTRACT}

Marx has gained attention again. His clarification of the functioning of capitalism contrasts with the neoclassic simplifications and the heterodox naivety. He stated the surplus value logic that underlies the neoliberal aggression and the kind of over-exploitation that prevails in precarious work. He clarified the origin of inequalities and the current sense of profits.

Das Kapital allows us to refute the identification of digital revolution with unemployment. It questions the crisis explanations based on governments' mistakes or the lack of regulations. It points out the inherent tensions in the consumption and the profitability fields.

Marx highlighted financial upheavals' production determinants. He suggested there are links between globalization and national patters of accumulation. He anticipated the polarizations that build the periphery's underdevelopment and the connections of anti-imperialism with socialist strategies.

He also conceptualized the combination of illusions and fear that the bourgeois ideology spreads. His egalitarian project rises again along with a new synthesis of political action and theoretical elaboration.

KEY WORDS: Marx, Das Kapital, capitalism, neoliberalism, Marxism.

La conmemoración del 150 aniversario de El capital ha renovado el debate sobre las contribuciones legadas por Marx a la comprensión de la sociedad actual. El texto continúa suscitando apasionadas adhesiones y fanáticos rechazos, pero ya no ejerce la enorme influencia que tuvo en los años 60 y 70 . Tampoco padece el olvido que acompañó al desplome de la Unión Soviética. Ningún investigador de peso ignora actualmente el significado del libro y las relecturas traspasan la academia e influyen sobre numerosos pensadores. 
El interés por Marx se verifica entre los economistas que resaltan su anticipación de la mundialización. Otros descubren una precoz interpretación de la degradación del medio ambiente y vinculan la ausencia de soluciones al desastre ecológico con la crisis civilizatoria que previó el teórico germano.

Su obra es retomada con mayor frecuencia para caracterizar la etapa neoliberal. Varios autores indagan las semejanzas de ese esquema con el "capitalismo puro" y desregulado que prevalecía en la época de Marx.

En un período de privatizaciones, apertura comercial y flexibilización laboral se transparentan rasgos del sistema que permanecieron ocultos durante la fase keynesiana. Los diagnósticos del pensador alemán recuperan nitidez en el siglo XXI.

La gran crisis que estalló en el 2008 reubicó a El capital en un lugar preponderante de la literatura económica. Ese desplome financiero no sólo desembocó en una impactante recesión. Precipitó además una expansión inédita del gasto público para socorrer a los bancos.

Marx recobra importancia en este escenario de agudos desequilibrios capitalistas. Por esta razón sus explicaciones del funcionamiento y la crisis del sistema son revisadas con gran atención.

Algunos analistas igualmente estiman que sus respuestas han perdido actualidad al cabo de 150 años. Es evidente que el régimen vigente es muy distinto al imperante en el período que conoció el escritor alemán. El registro de estas diferencias contribuye a evitar búsquedas dogmáticas de lo "ya dicho por Marx" sobre acontecimientos que lo sucedieron.

Pero conviene también recordar que el estudioso germano investigó el mismo modo de producción que opera en la actualidad. Ese régimen continúa regulado por las mismas leyes y sujeto a los mismos principios. Todas las denominaciones que ocultan esa persistencia (economía a secas, mercado, modernidad, posindustrialismo) obstruyen la comprensión del capitalismo de nuestra era.

La obra de Marx mantendrá su interés mientras subsista una estructura económico-social gobernada por la competencia, el beneficio y la explotación. ¿Pero cuáles son los señalamientos más pertinentes de su teoría para clarificar el modelo neoliberal actual? 


\section{REFUTACIONES FALLIDAS}

Marx captó la especificidad del capitalismo corrigiendo las inconsistencias de sus antecesores de la economía política clásica. Mantuvo la indagación totalizadora de la economía que encararon Smith y Ricardo superando las ingenuidades de la "mano invisible". Al descubrir las obstrucciones que afronta el capitalismo revolucionó el estudio de ese modo de producción.

$\mathrm{El}$ autor de El capital comprendió que esas tensiones son inherentes al sistema. Destacó que los desequilibrios no provienen del comportamiento o la irracionalidad de los individuos, ni obedecen a la inadecuación de las instituciones.

Marx postuló que el capitalismo está corroído por contradicciones singulares y distintas a las prevalecientes en regímenes anteriores. Esa comprensión le permitió transformar las críticas intuitivas en una impugnación coherente del capitalismo.

La ortodoxia neoclásica intentó refutar sus cuestionamientos con burdos panegíricos del sistema. Concibió insostenibles fantasías de mercados perfectos, consumidores racionales y efectos benévolos de la inversión. Recurrió a un cúmulo de mitos inverosímiles que contrastan con las aproximaciones realistas asumidas por Marx.

Los precursores del neoliberalismo no lograron desmentir el carácter intrínseco de los desequilibrios capitalistas. Ensayaron una presentación forzada de esas tensiones como resultado de injerencias estatales, sin explicar por qué razón el propio sistema recrea tantos desajustes.

Los criterios neoclásicos de maximización -complementados con las sofisticadas formalizaciones para seleccionar alternativas- ignoran la lógica general de la economía. Reducen la indagación de esa disciplina a un simple adiestramiento en ejercicios de optimización.

El predicamento actual de ese enfoque no proviene por lo tanto de su solidez teórica. Es apuntalado por las clases dominantes para propagar justificaciones de los atropellos a los asalariados. Instrumentan esas agresiones alegando exigencias naturales de la economía. Subrayan, por ejemplo, la imposibilidad de satisfacer los reclamos populares por restricciones derivadas de la escasez. Pero omiten el carácter relativo de esas limitaciones presentándolas como datos atemporales o invariables. 
La hostilidad de los neoclásicos hacia Marx contrasta con el reconocimiento exhibido por el grueso de la heterodoxia. Algunos autores de esa vertiente han buscado incluso la integración de la economía marxista, a un campo común de opositores a la teoría neoclásica. Esa pretensión ilustra áreas de afinidad, pero olvida que la concepción forjada a partir de El capital conforma un cuerpo contrapuesto a la herencia de Keynes.

La principal diferencia entre ambas visiones radica en la valoración del capitalismo. La heterodoxia acepta el carácter conflictivo del sistema, pero considera que esas tensiones pueden resolverse mediante una adecuada acción estatal.

Marx postuló, en cambio, que esa intervención sólo pospone (y finalmente agrava) los desequilibrios que pretende resolver. Con ese señalamiento colocó los cimientos de una tesis de gran actualidad: la imposibilidad de forjar modelos de capitalismo humano, redistributivo o regulado. Este planteo ordena todo el pensamiento marxista contemporáneo.

\section{PLUSVALÍA Y SUPEREXPLOTADOS}

Marx formuló observaciones sustanciales para entender el deterioro actual del salario. El modelo neoliberal ha generalizado esa retracción al intensificar la competencia internacional. La apertura comercial, la presión por menores costos y el imperio de la competitividad son utilizados para achatar los ingresos populares en todos los países. Los patrones recurren a un chantaje de relocalización de plantas -o a desplazamientos efectivos de la industria a Orientepara abaratar la fuerza de trabajo.

Ese atropello obedece a las crecientes tasas de explotación que exige la acumulación. Marx esclareció la lógica de esta presión al distinguir el trabajo de la fuerza de trabajo, al separarlas labores necesarias de las excedentes y al registrar qué porción de la jornada laboral remunera efectivamente el dueño de la empresa.

Con esa exposición ilustró cómo opera la apropiación patronal del trabajo ajeno. Señaló que esa confiscación queda enmascarada por la novedosa coerción económica que impera bajo el capitalismo. A diferencia del esclavo o el vasallo el asalariado es formalmente libre, pero está sometido a las reglas de supervivencia que imponen sus opresores. 
Marx fundamentó este análisis en su descubrimiento de la plusvalía. Demostró que la explotación es una necesidad del sistema. Pero también remarcó que la caída del salario es un proceso periódico y variable. Destacó que depende de procesos objetivos (productividades, base demográfica), coyunturales (ciclo de prosperidad o recesión) y subjetivos (intensidad y desenlace de la lucha de clases).

Esta caracterización permite entender que el trasfondo del atropello neoliberal en curso es una generalizada compulsión capitalista a elevar la tasa de plusvalía. Indica también que la intensidad y el alcance de esta agresión están determinados por las condiciones económicas, sociales y políticas vigentes en cada país.

La teoría del salario de Marx se ubica en las antípodas de las falacias neoclásicas de retribución al esfuerzo del trabajador. También rechaza la ingenuidad heterodoxa de mejoras invariablemente acordes a la redistribución del ingreso.

Pero es un enfoque alejado de cualquier postulado de "miseria creciente". El teórico alemán nunca pronosticó el inexorable empobrecimiento de todos los asalariados bajo el capitalismo. La significativa mejora del nivel de vida popular durante la posguerra corroboró esas prevenciones.

En la etapa neoliberal el salario vuelve a caer por la necesidad cíclica que afronta el capitalismo de acrecentar la tasa de plusvalía, mediante recortes a las remuneraciones de los trabajadores.

Marx postuló además un segundo tipo de caracterizaciones referidas a los desocupados de su época, que tiene especial interés para la actual comprensión de la exclusión. Este flagelo obedece presiones de la acumulación semejantes a las estudiadas por el pensador germano, en su evaluación de situaciones de pauperización absoluta.

El intelectual europeo quedó muy impactado por las terribles consecuencias del desempleo estructural. Ilustró con estremecedoras denuncias las condiciones inhumanas de supervivencia afrontadas por los empobrecidos. Esos retratos vuelven a cobrar actualidad en los escenarios de pérdida definitiva del empleo y consiguiente degradación social. Lo que Marx indagó en su descripción del "leprosario de la clase obrera", reaparece hoy en el drama de los sectores agobiados por la tragedia de la subsistencia. 
El neoliberalismo ha extendido la pauperización a gran parte de los trabajadores informales o flexibilizados. Esos segmentos soportan no sólo situaciones de sujeción laboral extrema, taylorización o descalificación, sino también remuneraciones del salario por debajo del valor de la fuerza de trabajo.

En las últimas décadas ese tormento no impera sólo en la periferia. La precarización se ha extendido a todos los rincones del planeta y se verifica en los centros. El nivel de los salarios continúa difiriendo en forma significativa entre los distintos países, pero la explotación redoblada se verifica en numerosas regiones. Es un padecimiento agudo en el centro y dramático en la periferia. Lo que Marx observaba en los desocupados de su época golpea también en la actualidad a gran parte de los precarizados de todas las latitudes.

\section{DESIGUALDAD Y ACUMULACIÓN}

Las ideas que expuso el autor de El capital permiten interpretar la explosión de desigualdad que recientemente midió Piketty. Los datos son escalofriantes. Un puñado de 62 enriquecidos maneja el mismo monto de recursos que 3600 millones de individuos. Mientras se desploma la seguridad social y se expande la pobreza, los acaudalados desfinancian los sistemas de previsión, escondiendo sus fortunas en paraísos fiscales.

La desigualdad no es el fenómeno pasajero que describen los teóricos ortodoxos. Los exponentes más realistas (o cínicos) de esa corriente explicitan la conveniencia de la inequidad para reforzar la sumisión de los asalariados.

La fractura social actual es frecuentemente atribuida a la preeminencia de modelos económicos regresivos. Pero Marx demostró que la desigualdad es inherente al capitalismo. Bajo este sistema las diferencias de ingresos varían en cada etapa, difieren significativamente entre países y están condicionadas por las conquistas populares o la correlación de fuerza entre opresores y oprimidos. Pero en todos los casos el capitalismo tiende a recrear y ensanchar las brechas sociales.

Marx atribuyó esa reproducción de la desigualdad, a la dinámica de un sistema asentado en ganancias derivadas de la plusvalía extraída a los trabajadores. El capital subraya ese rasgo en polémica con otras interpretaciones del beneficio, centradas en la astucia del comerciante. También objeta las caracterizaciones que subrayan retribuciones a la contribución del empresario, sin especificar en qué consisten esos aportes. 
Los neoclásicos nunca lograron refutar estos planteos, con su presentación de la ganancia como un premio a la abstinencia del consumo o al ahorro individual. Más insatisfactorias fueron sus caracterizaciones de retribuciones a un inanimado "factor capital" o a pagos de funciones gerenciales divorciadas de la propiedad de la empresa.

Desaciertos parecidos cometieron los keynesianos, al interpretar al lucro como una contraprestación al riesgo o a la innovación. Los pensadores más contemporáneos de esa escuela han optado por soslayar cualquier referencia al origen del beneficio.

Otros teóricos reconocen la inequidad del sistema, pero reducen el origen de la desigualdad a anomalías en la distribución del ingreso, derivadas de favoritismos o políticas erróneas. Nunca conectan esos procesos con la dinámica objetiva del capitalismo.

Las caracterizaciones convencionales de la ganancia son más insostenibles en el siglo XXI que en la época de Marx. Nadie puede explicar con criterios usuales, la monumental fortuna acumulada por el 1\% de billonarios globales. Esos lucros están más naturalizados que en el pasado sin justificaciones de ninguna índole.

Las críticas en boga al enriquecimiento cuestionan a lo sumo las escandalosas ganancias de los banqueros. Ponderan en cambio los beneficios surgidos de la producción, sin evaluar las conexiones entre ambas formas de rentabilidad.

La relectura de El capital permite recordar que la tajada obtenida por los banqueros, constituye tan sólo una porción de la masa total de beneficios creada con la explotación de los trabajadores.

Marx analizó también las formas violentas que en ciertas circunstancias asume la captura de ganancias. Evaluó esa tendencia en estudios de la acumulación primitiva, que han sido actualizados por los teóricos de la acumulación por desposesión (Harvey).

En El capital investigó las formas coercitivas que presentó la apropiación de recursos en la génesis del capitalismo. Pero el sistema continuó recreando esas exacciones en distintas situaciones de la centuria y media posterior. Las guerras de Medio Oriente, los saqueos de África o las expropiaciones de campesinos en Asia ilustran modalidades recientes de esa succión.

Marx inauguró los estudios de formas excepcionales de confiscación del trabajo ajeno. Esa investigación sentó las bases para clarificar la dinámica contemporánea de la inflación y la deflación. 
$\mathrm{Al}$ igual que sus precursores clásicos Marx postuló una determinación objetiva de los precios en función de su valor. Precisó que esa magnitud queda establecida por el tiempo de trabajo socialmente necesario para la producción de los bienes, en convulsivos procesos de extracción de plusvalía y realización del valor.

Esa caracterización no sólo permite refutar la ingenua presentación neoclásica de los precios como reflejos de la utilidad personal, o como espontáneos emergentes de la oferta y la demanda. También desmonta la absurda imagen del capitalista, como víctima de escaladas inflacionarias o deflacionarias ajenas a su conducta.

En las coyunturas críticas, la determinación turbulenta de los precios reditúa ganancias extraordinarias a los grandes patrones por medio de abruptas desvalorizaciones del salario. Esos mecanismos operan en la actualidad, con la misma intensidad que las expropiaciones virulentas de la época de Marx.

El capital facilitó la identificación posterior de quiénes son los artífices y beneficiarios del nivel que asumen los precios. Esa caracterización no se limita a retratar situaciones de "pugna distributiva". Subraya la desigualdad de condiciones en que disputan los trabajadores con sus patrones y resalta la consiguiente dominación que ejercen los formadores de precios.

\section{DESEMPLEO E INNOVACIÓN}

La masificación actual del desempleo constituye otra razón para releer a Marx. Algunos pensadores neoclásicos asumen esa calamidad como un simple dato. Otros difunden consuelos sobre la futura potencialidad de los servicios, para compensar la caída del empleo industrial. Esas previsiones no se corroboran en ningún país.

Muchos analistas afirman que la educación resolverá el problema. Pero olvidan mencionar el creciente número de desocupados con títulos universitarios. La destrucción de puestos de trabajo ya afecta severamente a los segmentos más calificados.

Distintas mediciones han comenzado a registrar que en el modelo actual el desempleo no se reduce en las fases expansivas, en proporción equivalente a su incremento en los periodos recesivos. Este flagelo se acrecienta con la rotación acelerada del capital y la reducción vertiginosa de los gastos administrativos.

La revolución digital es invariablemente mencionada como la principal causa de esta creciente pérdida de puestos de trabajo. Pero las computadoras son culpabilizadas omitiendo quiénes definen su utilización. Se olvida que esos 
instrumentos nunca actúan por sí mismos. Son gestionados por capitalistas que apuntalan sus beneficios sustituyendo mano de obra. La informática y la automatización no destruyen espontáneamente el empleo. La rentabilidad empresarial provoca esa demolición.

El capital introdujo los principales fundamentos de esta caracterización del cambio tecnológico. Marx afirmó que las innovaciones son incorporadas para incrementar la tasa de explotación que nutre el beneficio patronal.

La revolución informática en curso se ajusta plenamente a ese postulado.Es un recurso utilizado por las grandes empresas para potenciar la captura del nuevo valor generado por los asalariados.

Tal como ocurrió en el pasado con el vapor, el ferrocarril, la electricidad o los plásticos, la digitalización introduce transformaciones radicales en la actividad productiva, comercial y financiera. Abarata el transporte y las comunicaciones y modifica por completo los procedimientos de fabricación o venta de las mercancías.

Un indicio de esa mutación es la influencia alcanzada por los "señores de las nubes". Siete de las diez empresas con mayor capitalización bursátil actual pertenecen al sector de nuevas tecnologías de la información. Hace una década y media las firmas con mayor espalda financiera eran petroleras, industriales o automotrices. Actualmente son Google, Amazon, Facebook o Twitter.

Esta irrupción suscita presagios venturosos entre los pensadores que ocultan las consecuencias de la gestión capitalista de la informática. Omiten, por ejemplo, que la masificación de la comunicación digital reforzó la privatización del espacio virtual. Ese ámbito es controlado por pocas empresas privadas estrechamente asociadas con el Pentágono. El capital permite entender los determinantes capitalistas de este perfil de la innovación.

Marx inició la indagación de la tecnología como un fenómeno social, abriendo un camino de estudios que floreció en las últimas décadas. Pero a diferencia de los teóricos evolucionistas o schumpeterianos demostró que el cambio tecnológico desestabiliza la acumulación y potencia la crisis.

La innovación guiada por principios de lucro impone una descarnada competencia que multiplica la sobreproducción. Induce además a jerarquizar el desenvolvimiento de ramas tan destructivas como la industria militar.

Marx explicó por qué razón el sistema actual impide una gestión social provechosa de las nuevas tecnologías. Señaló que ese manejo requeriría 
introducir criterios cooperativos opuestos a los principios de rentabilidad. Las potencialidades de la informatización como instrumento de bienestar y solidaridad, sólo emergerán en una sociedad emancipada del capitalismo.

\section{MULTIPLICIDAD DE CRISIS}

Actualmente Marx suscita especial interés por los criterios que enunció para interpretar las crisis. El neoliberalismo no sólo genera crecientes sufrimientos populares. Cada quinquenio o decenio desencadena convulsiones que conmocionan a la economía mundial. Esos estallidos inducen a estudiar El capital.

Las crisis del último período incluyeron la burbuja japonesa (1993), la eclosión del Sudeste Asiático (1997), el desplome de Rusia (1998), el desmoronamiento de las Punto.Com (2000) y el descalabro de Argentina (2001). Pero la magnitud y el alcance geográfico del temblor global del 2008 superaron ampliamente esos antecedentes. Su impacto obligó a revisar todas las teorías económicas.

Las crisis recientes son efectos directos de la nueva etapa de privatizaciones, apertura comercial y flexibilidad laboral. No son prolongaciones de tensiones irresueltas de los años 70. Emergieron al calor de los desequilibrios peculiares del neoliberalismo.

Ese modelo erosionó los diques que morigeraban los desajustes del sistema. Por esa razón el capitalismo actual opera con grados de inestabilidad muy superiores al pasado.

Los neoclásicos atribuyeron la crisis del 2008 a desaciertos de los gobiernos o irresponsabilidades de los deudores. Redujeron todos los problemas a comportamientos individuales, culpabilizaron a las víctimas y apañaron a los responsables. Justificaron además los socorros estatales a los bancos, sin registrar que esos auxilios contrarían todas sus prédicas a favor de la competencia y el riesgo.

Los heterodoxos explicaron las mismas convulsiones por eldescontrol del riesgo. Olvidaron que esas supervisiones son periódicamente socavadas por las rivalidades entre empresas o bancos. Las normas que protegen los negocios de las clases dominantes son quebrantadas por la propia continuidad de la acumulación.

La relectura de El capital permite superar esas inconsistencias de la economía convencional. Induce a investigar el origen sistémico de esos estallidos. Brinda 
pistas para indagar los diversos mecanismos de la crisis, recordando que el capitalismo despliega una amplia gama de contradicciones.

El cimiento común de esos desequilibrios es la generación periódica de excedentes invendibles. Pero esa sobreproducción se desenvuelve por varios carriles complementarios.

Marx resaltó la existencia de tensiones entre la producción y el consumo, derivadas de la estratificación clasista de la sociedad. Esta caracterización tiene gran aplicación en el escenario de agudos problemas de realización del valor de las mercancías, que ha generado el neoliberalismo.

Ese modelo propicia una ampliación de los consumos sin permitir su disfrute. Expande la producción estrechando los ingresos populares y precipita crisis derivadas del deterioro del poder adquisitivo. El enorme engrosamiento del endeudamiento familiar no atenúa la vulnerabilidad de la demanda.

Marx fue el primero en ilustrar cómo la competencia obliga a los empresarios a desenvolver dos tendencias opuestas. Por un lado amplían las ventas y por otra parte reducen los costos salariales. Esa contradicción presenta envergaduras y localizaciones muy distintas en cada época.

El neoliberalismo estimula en la actualidad el consumismo y la riqueza patrimonial financiada con endeudamiento en las economías centrales. Al mismo tiempo impone brutales retracciones del poder de compra en la periferia.

El capital también pone el acento en los problemas de valorización. Indaga cómo opera la tendencia decreciente de la tasa de ganancia. Demuestra que el aumento de la inversión produce una declinación porcentual del beneficio, al compás de la propia expansión de la acumulación. El trabajo vivo que nutre a la plusvalía decae proporcionalmente, con el incremento de la productividad que impone la competencia.

Marx resaltó que las crisis emergen del crecimiento capitalista. No son efectos ocasionales del despilfarro o del uso inadecuado de los recursos. Explicó, además, cómo el sistema contrapesa primero y agrava después la caída periódica de la tasa de beneficio.

Esta tesis permite entender de qué forma el neoliberalismo incrementó la tasa de plusvalía, redujo los salarios y abarató los insumos para contrarrestar el declive del nivel de rentabilidad. También ilustra cómo el mismo problema reaparece al cabo de esa cirugía. La contradicción descubierta por Marx se verifica 
actualmente en las economías más capitalizadas que padecen desajustes de sobreinversión.

La presentación marxista combinada de los desequilibrios de realización y valorización es muy pertinente para comprender la heterogeneidad de la mundialización neoliberal. Indica que contradicciones de ambos tipos irrumpen en los distintos polos de ese modelo y socavan su estabilidad desde flancos complementarios.

\section{FINANZAS Y PRODUCCIÓN}

Marx siempre subrayó los determinantes productivos de las crisis capitalistas. En el marco de las enormes transformaciones generadas por la globalización, ese señalamiento permite evitar lecturas simplistas en clave puramente financiera.

Los grandes capitales se desplazan actualmente de una actividad especulativa a otra, en escenarios altamente desregulados que acrecientan las explosiones de liquidez. La gestión accionaria de las firmas potencia además los desajustes crediticios, la inestabilidad cambiaria y la volatilidad bursátil.

Ese proceso multiplica las tensiones suscitadas por los nuevos mecanismos de titularización, derivados y apalancamientos. Es evidente que el neoliberalismo abrió las compuertas para un gran festival de especulación.

Pero hace 150 años Marx demostró que esas alocadas apuestas son propias del capitalismo. La especulación es una actividad constitutiva y no opcional del sistema. Alcanzó dimensiones mayúsculas en las últimas tres décadas, pero no constituye un rasgo exclusivo del modelo actual.

Esta precisión permite observar las conexiones entre desequilibrios financieros y productivos que resalta El capital. Marx describió las tensiones autónomas de la primera esfera, pero remarcó que en última instancia derivan de transformaciones registradas en el segundo ámbito.

Siguiendo esta pista se puede notar que la hegemonía actual de las finanzas constituye sólo un aspecto de la reestructuración en curso. No es un dato estructural del capitalismo contemporáneo. La clase dominante utiliza el instrumento financiero para recomponer la tasa de ganancia mediante mayores exacciones de plusvalía. 
La globalización financiera está enlazada además con el avance de la internacionalización productiva. La multiplicidad de títulos en circulación es funcional a una gestión más compleja del riesgo. Permite administrar actividades fabriles o comerciales mundializadas y sujetas a inesperados vaivenes de los mercados.

También la expansión del capital ficticio está vinculada a esos condicionantes y evoluciona en concordancia con los movimientos del capital-dinero. Aprovisiona a la producción e intermedia en la circulación de las mercancías.

Estas conexiones explican la persistencia de la globalización financiera luego de la crisis del 2008. Los capitales continúan fluyendo de un país a otro con la misma velocidad y libertad de circulación, para aceitar el funcionamiento de estructuras capitalistas más internacionalizadas.

Es cierto que todos los intentos de reintroducir controles a los bancos fallaron por la resistencia que opusieron financistas. Pero esa capacidad de veto ilustra el entrelazamiento del mundo del dinero con el universo productivo. Son dos facetas de un mismo proceso de internacionalización.

El capital aporta numerosas observaciones de la dinámica financiera que explican esos vínculos, a partir de una interpretación muy original de la lógica del dinero. Destaca el insustituible papel de la moneda en la intermediación de todo el proceso de reproducción del capital. Remarca que las distintas funciones del dinero en la circulación, el atesoramiento o el despliegue de los medios de pago están sujetan a la misma lógica objetiva, que regula todo el desenvolvimiento de las mercancías.

Ese rol ha presentado modalidades muy distintas en los diversos regímenes de regulación monetaria. El patrón oro del siglo XIX diverge significativamente de las paridades actualmente administradas por los bancos centrales. Pero en todos los casos rige un curso determinado por la dinámica de la acumulación, la competencia y la plusvalía.

El capital contribuye a recordar estos fundamentos no sólo en contraposición a los mitos ortodoxos de transparencia mercantil, asignación óptima de los recursos o vigencia de monedas exógenas, neutrales y pasivas.

También pone de relieve las ingenuidades heterodoxas. Marx no presentó a la moneda como una mera representación simbólica, un mecanismo convencional o un instrumento amoldado al marco institucional. Explicó su necesario rol para los sucesivos tránsitos entre los circuitos comerciales, productivos y financieros. 


\section{ECONOMÍA MUNDIAL Y NACIONAL}

La centralidad que tiene El capital para comprender la dinámica contemporánea de los salarios, la desigualdad, el desempleo o la crisis debería conducir a una revisión general de sus aportes a la teoría económica. Resultaría muy oportuno actualizar por ejemplo, el estudio de las controversias suscitadas por ese libro que realizó Mandel, en el centenario de la primera edición.

La obra del pensador germano no sólo esclarece el sentido de las categorías básicas de la economía. También sugiere líneas de investigación para comprender la mundialización en curso. Marx nunca llegó a escribir el tomo que preparaba sobre la economía internacional, pero esbozó ideas claves para entender la lógica globalizadora del sistema.

Esos principios son muy relevantes en el siglo XXI. El capitalismo funciona en la actualidad al servicio de gigantescas empresas transnacionales, que corporizan el salto registrado en la internacionalización. La producción de Wal-Mart es mayor que las ventas de un centenar de países, la dimensión económica de Mitsubishi desborda el nivel de actividad de Indonesia y General Motors supera la escala de Dinamarca.

Las firmas globalizadas diversificaron sus procesos de fabricación encadenas de valor y mercancías "hechas en el mundo". Desenvuelven todos sus proyectos productivos, en función de las ventajas que ofrece cada localidad en materia de salarios, subsidios o disponibilidad de recursos.

La expansión de los tratados de libre-comercio se amolda a esa mutación. Las compañías necesitan bajos aranceles y libertad de movimientos, para concretar transacciones entre sus firmas asociadas. Por eso imponen convenios que consagran la supremacía de las empresas en cualquier litigio judicial. Esos pleitos son decisivos en ciertas áreas como la genética, la salud o el medio ambiente.

Una relectura de El capital permite superar dos errores muy corrientes en la interpretación de la internacionalización en curso. Un equívoco supone que el capitalismo actual se maneja con los mismos patrones de preeminencia nacional, que regían en los siglos XIX o XX. El desacierto opuesto considera que el sistema se globalizó por completo, eliminando las barreras nacionales, disolviendo el papel de los estados y forjando clases dominantes totalmente transnacionalizadas.

Marx escribió su principal obra en una etapa de formación del capitalismo muy distinta al contexto actual. Pero conceptualizó acertadamente cómo operan las tendencias hacia la mundialización en el marco de los estados y las economías 
nacionales. Ha cambiado la proporción y relevancia comparativa de esa mixtura, pero no la vigencia de esa combinación.

El capital mejoró las ideas expuestas en el Manifiesto Comunista sobre el carácter internacional de la expansión burguesa. En el primer ensayo Marx había retratado la gestación de un mercado mundial, la pujanza del cosmopolitismo económico y la veloz universalización de las reglas mercantiles. En su libro de madurez precisó las formas que asumían esas tendencias y remarcó su enlace con los mecanismos nacionales del ciclo y la acumulación.

Marx ajustó su mirada de la internacionalización objetando las tesis ricardianas de las "ventajas comparativas". Resaltó el carácter estructural de la desigualdad imperante en el comercio internacional. Por eso rechazó todas las expectativas de convergencia armoniosa entre países y las visiones de amoldamiento natural a las aptitudes de los concurrentes.

Este enfoque le permitió notar la vigencia de remuneraciones internacionales más elevadas para los trabajos de mayor productividad. En el debut del capitalismo Marx percibió algunos fundamentos de explicaciones posteriores de la brecha en los términos de intercambio.

El teórico germano también observó la secuela de desajustes generados por el desborde capitalista de las fronteras nacionales. Registró cómo ese proceso provoca crecientes fracturas a escala global.

Pero El capital investigó esa dinámica en escenarios nacionales muy específicos. Indagó la evolución de los salarios, los precios o la inversión en economías particulares. Detalló puntualmente esa dinámica en el desenvolvimiento industrial de Inglaterra.

La lectura de Marx invita, por lo tanto, a evaluar la mundialización actual como un curso preeminente, que coexiste con el continuado desenvolvimiento nacional de la acumulación. Sugiere que ambos procesos operan en forma simultánea.

\section{POLARIDADES CON NUEVO RAZONAMIENTO}

El capital es muy útil también para analizar la lógica de la relación centroperiferia subyacente en la brecha global actual. Marx anticipó ciertas ideas sobre esa división, en sus observaciones sobre desenvolvimiento general del capitalismo. 
Al principio suponía que los países retrasados repetirían la industrialización de Occidente. Estimaba que el capitalismo se expandía demoliendo murallas y creando un sistema mundial interdependiente.

Expuso esa visión en el Manifiesto Comunista. Allí describió cómo China e India serían modernizadas con el ferrocarril y la importación de textiles británicos. Marx realzaba la dinámica objetiva del desarrollo capitalista y consideraba que las estructuras precedentes serían absorbidas por el avance de las fuerzas productivas.

Pero al redactar El capital comenzó a percibir tendencias opuestas. Notó que la principal potencia se modernizaba ampliando las distancias con el resto del mundo. Esta aproximación se afianzó con su captación de lo ocurrido en Irlanda. Quedó impresionado por la forma en que la burguesía inglesa sofocaba el surgimiento de manufactureras en la isla, para garantizar el predominio de sus exportaciones. Notó, además, cómo se aprovisionaba de fuerza de trabajo barata para limitar las mejoras de los asalariados británicos.

En esta indagación intuyó que la acumulación primitiva no anticipa procesos de pujante industrialización, en los países sometidos al yugo colonial. Este registro sentó las bases para la crítica posterior a las expectativas de simple arrastre de la periferia por el centro. Con este fundamento se conceptualizó posteriormente la lógica del subdesarrollo.

Marx no expuso una teoría del colonialismo, ni una interpretación de la relación centro-periferia. Pero dejó una semilla de observaciones para comprender la polarización global, que retomaron sus sucesores y los teóricos de la dependencia.

Esta línea de trabajo es muy relevante para notar cómo en la actualidad el neoliberalismo exacerba las fracturas globales. En las últimas tres décadas se ampliaron todas las brechas que empobrecen a la periferia inferior. Esa degradación se intensificó con la consolidación del agro-negocio, el endeudamiento externo y el avasallamiento de los recursos naturales de los países dependientes. Estas confiscaciones asumieron modalidades muy sangrientas en África y el mundo árabe.

Las observaciones de Marx incluyeron también cierto registro de diversidades en el centro. Intuyó que el debut industrial británico no sería copiado por Francia y notó la presencia de cursos novedosos de crecimiento mixturados con servidumbre (Rusia) o esclavismo (Estados Unidos). 
El autor de El capital captó esas tendencias madurando un cambio de paradigma conceptual. En sus trabajos más completos reemplazó el primer enfoque unilineal -asentado en el comportamiento de las fuerzas productivas- por una mirada multilineal, centrada en el papel transformador de los sujetos.

Con este último abordaje la rígida cronología de periferias amoldadas a la modernización quedó sustituida por nuevas visiones, que reconocen la variedad del desenvolvimiento histórico.

Esta metodología de análisis es importante para notar la especificidad de las formaciones intermedias, que han irrumpido en forma persistente en distintos periodos de la última centuria y media. Con esa óptica se puede evaluar la dinámica de acelerados procesos de crecimiento contemporáneo (China), en etapas de gran reorganización del sistema (neoliberalismo).

\section{ANTICIPOS DE ANTIIMPERIALISMO}

Marx estudió la economía del capitalismo para notar su efecto sobre la lucha de clases que socava al sistema. Por eso indagó los procesos políticos revolucionarios a escala internacional.

Siguió con especial interés el curso de las rebeliones populares de China, India y sobre todo Irlanda e intuyó la importancia de los nexos entre las luchas nacionales y sociales. Por eso promovió la adhesión de los obreros británicos a la revuelta de la isla contigua, buscando contrarrestarlas divisiones imperantes entre los oprimidos de ambos países.

A partir de esa experiencia Marx ya no concibió la independencia de Irlanda, como un resultado de victorias proletarias en Inglaterra. Sugirió un empalme entre ambos procesos y transformó su internacionalismo cosmopolita inicial, en un planteo de confluencia de la resistencia anticolonial con las luchas en las economías centrales.

En su etapa del Manifiesto el revolucionario alemán propagaba denuncias anticoloniales de alto voltaje. No se limitaba a describir la destrucción de las formas económicas pre-capitalistas. Cuestionaba a viva voz las atrocidades de las grandes potencias.

Pero en esos trabajos juveniles Marx suponía que la generalización del capitalismo aceleraría la erradicación ulterior de ese sistema. Defendía un internacionalismo proletario muy básico y emparentado con viejas utopías universalistas. 
En su mirada posterior Marx resaltó el efecto positivo de las revoluciones en la periferia. Esos señalamientos fueron retomados por sus discípulos del siglo XX, para indicar la existencia de una contraposición entre potencias opresoras y naciones oprimidas y postular la convergencia de batallas nacionales y sociales. De esas caracterizaciones surgieron las estrategias de alianza de los asalariados metropolitanos con los desposeídos del mundo colonial.

Con este fundamento se forjó también la síntesis del socialismo con el antiimperialismo, que desenvolvieron los teóricos del marxismo latinoamericano. Esa conexión indujo las convergencias de la izquierda regional con el nacionalismo revolucionario, para confrontar con el imperialismo estadounidense. Ese empalme inspiró a la revolución cubana y ha sido retomado por el proceso bolivariano.

En una coyuntura signada por las agresiones de Trump ese acervo de experiencias recobra importancia. Los atropellos del magnate inducen a revitalizar las tradiciones antiimperialistas, especialmente en países tan vapuleados como México. Allí resurge la memoria de resistencias a los avasallamientos perpetrados por Estados Unidos.

Marx observaba cómo las grandes humillaciones nacionales desatan procesos revolucionarios. Lo que percibió en el siglo XIX vuelve a gravitar en la actualidad.

\section{ADVERSIDADES E IDEOLOGÍA}

Marx debió lidiar con momentos de aislamiento, reflujo de la lucha popular y consolidación del dominio burgués. La escritura de varias partes de El capital coincidió con esas circunstancias. Afrontó la misma adversidad que prevalece en la actualidad en las coyunturas de estabilización del neoliberalismo.

En ese tipo de situaciones el pensador germano indagó cómo domina la clase dominante. Conceptualizó el papel de la ideología en el ejercicio de esa supremacía. En el estudio del fetichismo de la mercancía que encaró en El capital hay varias referencias a esa problemática.

Es importante retomar esas consideraciones para notar cómo ha funcionado el neoliberalismo en las últimas décadas. Los artífices del modelo actual transmiten fantasías de sabiduría de los mercados e ilusiones de prosperidad espontánea. Presagian derrames del beneficio y recrean numerosas mitologías del individualismo. 
Con esa batería de falsas expectativas propagan una influyente ideología en todos los sentidos del término. Marx destacó esa variedad de facetas de las creencias propagadas por los dominadores para naturalizar su opresión.

El credo neoliberal provee todos los argumentos utilizados por el establishment para justificar su primacía. Aunque el grado de penetración de esas ideas es muy variable, salta a la vista su incidencia en la subjetividad de todos los individuos.

Pero al igual que en la época de Marx el capitalismo se reproduce también a través del miedo. El sistema transmite creencias sobre un futuro venturoso y al mismo tiempo generaliza el pánico ante ese devenir. El neoliberalismo ha multiplicado especialmente la angustia del desempleo, la humillación frente a la flexibilidad laboral y la desesperanza ante la fractura social.

Esos temores son transmitidos por los grandes medios de comunicación con sofisticados disfraces y cambiantes engaños. No sólo configuran el sentido común imperante en la sociedad. Operan como usinas de propagación de todos los valores conservadores.

Los medios de comunicación complementan (o sustituyen) a las viejas instituciones escolares, militares o eclesiásticas en el sostenimiento del orden burgués. La prensa escrita, los medios audiovisuales y las redes sociales ocupan un espacio inimaginable en el siglo XIX. Expanden las ilusiones y los temores que sostienen la hegemonía política del neoliberalismo.

Pero esos mecanismos han quedado seriamente erosionados por la pérdida de legitimidad que genera el descontento popular. Trump, el Brexit o el ascenso de los partidos reaccionarios en Europa, ilustran cómo ese malestar puede ser capturado por la derecha. Frente a este tipo de situaciones Marx forjó una perdurable tradición deconcebir alternativas, combinando la resistencia con la comprensión de la coyuntura.

\section{PROYECTO SOCIALISTA}

Marx participó activamente en los movimientos revolucionarios que debatían las ideas del socialismo y el comunismo. Mantuvo esa intensa intervención mientras escribía El capital. Nunca detalló su modelo de sociedad futura pero expuso los basamentos de ese porvenir.

El acérrimo crítico de la opresión alentaba la gestación de regímenes económicos asentados en la expansión de la propiedad pública. También promovía la creación de sistemas políticos cimentados en la auto-administración popular. 
Marx apostaba a un pronto debut de esos sistemas en Europa. Percibió en la Comuna de París un anticipo de su proyecto. Concebía el inicio de esa transformación revolucionaria en el Viejo Continente e imaginaba una propagación ulterior a todo el planeta.

Es sabido que la historia siguió una trayectoria muy diferente. El triunfo bolchevique de 1917 inauguró la secuencia de grandes victorias populares del siglo XX. Esos avances incluyeron intentos de construcción socialista en varias regiones de la periferia.

Las clases dominante quedaron aterrorizadas y otorgaron concesiones inéditas para contener la pujanza de los movimientos anticapitalistas. En los años 70-80 los emblemas del socialismo eran tan populares, que resultaba imposible computar cuántos partidos y movimientos reivindicaban esa denominación.

Pero también es conocido lo ocurrido posteriormente. El desplome de la Unión Soviética dio lugar al prolongado periodo de reacción contra el igualitarismo, que persiste hasta la actualidad.

Este escenario ha sido alterado por la resistencia popular y el declive del modelo político-ideológico que nutrió a la globalización neoliberal. En estas circunstancias la relectura de El capital converge con redescubrimientos del proyecto socialista. Los jóvenes ya no cargan con los traumas de la generación anterior, ni con las frustraciones que pavimentaron la implosión de la URSS.

La propia experiencia de lucha es aleccionadora. Muchos activistas comprenden que la conquista de la democracia efectiva y la igualdad real exige forjar otro sistema social. Frente al sufrimiento que ofrece el capitalismo intuyen la necesidad de construir un horizonte de emancipación.

La llegada de Trump incorpora nuevos ingredientes a esta batalla. El acaudalado mandatario intenta recuperar por la fuerza la primacía de Estados Unidos. Pretende reforzar la preponderancia de Wall Street y la preeminencia del lobby petrolero, reactivando el unilateralismo bélico.

No sólo proclama que Estados Unidos debe alistarse para "ganar las guerras". Ya inició su programa militarista con bombardeos en Siria y Afganistán. Exige, además, una subordinación del Viejo Continente que socava la continuidad de la Unión Europea. Trump no se limita a construir el muro en la frontera mexicana. Acelera la expulsión de inmigrantes, alienta golpes derechistas en Venezuela y amenaza a Cuba. 
En esta convulsionada coyuntura Marx recobra actualidad. Sus textos no sólo aportan una guía para comprender la economía contemporánea. También ofrecen ideas para la acción política en torno a tres ejes primordiales del momento: reforzar la resistencia antiimperialista, multiplicar la batalla ideológica contra el neoliberalismo y afianzar la centralidad del proyecto socialista.

\section{ACTITUDES Y COMPROMISOS}

Las teorías que introdujo Marx revolucionaron todos los parámetros de la reflexión y trastocaron los cimientos del pensamiento social. Pero el teórico alemán sobresalió también como un gran luchador. Desenvolvió un tipo de vida que actualmente identificaríamos con la militancia.

Marx se ubicó en el bando de los oprimidos. Reconoció los intereses sociales en juego y rechazó la actitud del observador neutral. Participó en forma muy decidida en la acción revolucionaria.

Ese posicionamiento orientó su trabajo hacia los problemas de la clase trabajadora. Promovió la conquista de derechos sociales con la mira puesta en forjar una sociedad liberada de la explotación.

Marx propició una estrecha confluencia de la elaboración teórica con la práctica política. Inauguró un modelo de fusión del intelectual, el economista y el socialista que ha sido retomado por numerosos pensadores.

Con esa postura evitó dos desaciertos: el refugio académico alejado del compromiso político y el deslumbramiento pragmático por la acción. Legó un doble mensaje de intervención en la lucha y trabajo intelectual para comprender la sociedad contemporánea. Continuar ese camino es el mejor homenaje a los 150 años de El capital.

\section{BIBLIOGRAFÍA}

AMIN, Samir (1973): ¿Cómo funciona el capitalismo?, Buenos Aires: Siglo XXI.

ANDERSON, Kevin B. (2010): Marx at the margins, Chicago: University Of Chicago Press.

BRAVERMAN, Harry (1980): Trabajo y capital monopolista, México: Nuestro Tiempo. 
BRUNHOFF, Suzanne (1973): La concepción monetaria de Marx, Ediciones del siglo.

CALLINICOS, Alex (1999): Social theory, Londres: Polity Press.

CARCHEDI, Guglielmo (1991): Frontiers of political economy, Londres: Verso.

DUMENIL, Gérard y LEVY, Dominique (1996): La dynamique du capital, París: PUF.

FOLEY, D. K. (1989): Para entender El capital, México: Fondo de cultura económica.

GROSSMAN, Henryk (1979): La ley de la acumulación y el derrumbe del sistema capitalista, México: Siglo XXI.

HARVEY, David (1982): Los límites del capitalismo y la teoría marxista, México: Fondo de Cultura Económica.

HILFERDING, Rudolf (1973): El capital financiero, Madrid: Tecnos.

HUSSON, Michel (2009): Capitalismo puro, Madrid: Maia.

KOHAN, Néstor (1998): Marx en su (Tercer) Mundo: hacia un socialismo no colonizado, Buenos Aires: Biblos.

LUXEMBURG, Rosa (1968): La acumulación del capital, Buenos Aires: s/e.

MANDEL, Ernest (1978): El capitalismo tardío, México: Era.

MANDEL, Ernest (1985): Cien años de controversias en torno a la obra de Karl Marx. Madrid: Siglo XXI.

MARX, Carlos (1973): El Capital, México: Fondo de Cultura Económica.

MARX, Carlos (1967): El Manifiesto Comunista, Buenos Aires: Claridad.

PANITCH, Leo y Sam GINDIN (2012): The Making of Global Capitalism, Londres: Verso.

PIKETTY, Thomas (2013): Le capital auXXIesiècle, París: Seuil.

ROSDOLSKY, Román (1979): Génesis y estructura de El capital, México: Siglo XXI.

RUBIN, Isaac (1985): “Ensayo sobre la teoría del valor”, México, Cuadernos de Pasado y Presente, n. 53.

SALAMA, Pierre y Tran HAI HAC (1992): Introduction a l'Economie de Marx, París: La Decouverte.

SHAIKH, Anwar (1991): Valor, acumulación y crisis, Bogotá: Tercer Mundo Editores.

SWEEZY, Paul (1973): Teoría del desarrollo capitalista, México: Fondo de Cultura Económica. 
El CaPitAl DE MARX: 151 AÑos DEL LIBRO I

Recibido: 2 de junio de 2017

Aceptado: 7 de febrero de 2018

Claudio Katz es economista, investigador del CONICET y profesor de la Universidad de BBAA, miembro del EDI. Sitio web: www.lahaine.org/katz. 